\title{
Global comparative transcriptome analysis of cartilage formation in
} vivo

\author{
Trevor L Cameron ${ }^{1}$, Daniele Belluoccio ${ }^{1}$, Peter G Farlie ${ }^{1}$, Bent Brachvogel ${ }^{1,2}$ \\ and John F Bateman*1
}

\begin{abstract}
Address: ${ }^{1}$ Murdoch Childrens Research Institute and Department of Paediatrics, University of Melbourne, Royal Children's Hospital, Parkville, Victoria 3052, Australia and ${ }^{2}$ Center for Biochemistry, Medical Faculty, University of Cologne, Germany

Email: Trevor L Cameron - trevor.cameron@mcri.edu.au; Daniele Belluoccio - dan.belluoccio@mcri.edu.au;

Peter G Farlie - peter.farlie@mcri.edu.au; Bent Brachvogel - bent.brachvogel@uni-koeln.de; John F Bateman* - john.bateman@mcri.edu.au

* Corresponding author
\end{abstract}

Published: 10 March 2009

BMC Developmental Biology 2009, 9:20 doi:10.1186/147/-2/3X-9-20

This article is available from: http://www.biomedcentral.com/I47I-213X/9/20

(C) 2009 Cameron et al; licensee BioMed Central Ltd.

This is an Open Access article distributed under the terms of the Creative Commons Attribution License (http://creativecommons.org/licenses/by/2.0), which permits unrestricted use, distribution, and reproduction in any medium, provided the original work is properly cited.
Received: 18 June 2008

Accepted: 10 March 2009

\begin{abstract}
Background: During vertebrate embryogenesis the initial stages of bone formation by endochondral ossification involve the aggregation and proliferation of mesenchymal cells into condensations. Continued growth of the condensations and differentiation of the mesenchymal cells into chondrocytes results in the formation of cartilage templates, or anlagen, which prefigure the shape of the future bones. The chondrocytes in the anlagen further differentiate by undergoing a complex sequence of maturation and hypertrophy, and are eventually replaced by mineralized bone. Regulation of the onset of chondrogenesis is incompletely understood, and would be informed by comprehensive analyses of in vivo gene expression.
\end{abstract}

Results: Tibial and fibular pre-condensed mesenchyme was microdissected from mouse hind limbs at $11.5 \mathrm{dpc}$, and the corresponding condensations at $12.5 \mathrm{dpc}$ and cartilage anlagen at $13.5 \mathrm{dpc}$. Total RNA was isolated, and cRNA generated by linear amplification was interrogated using mouse whole genome microarrays. Differential expression was validated by quantitative PCR for Agcl, Bmp8a, Col2al, Fgfr4, Foxa3, Gdf5, KIf2, KIf4, Leprel, Ncad, SoxI I, and Trpv4. Further, independent validation of the microarray data was achieved by in situ hybridization to analyse the expression of LepreI, Pcdh8, Sox II, and Trpv4 from II.5 dpc to $13.5 \mathrm{dpc}$ during mouse hind limb development. We found significant differential expression of 931 genes during these early stages of chondrogenesis. Of these, 380 genes were down-regulated and $55 \mathrm{I}$ up-regulated. Our studies characterized the expression pattern of gene families previously associated with chondrogenesis, such as adhesion molecules, secreted signalling molecules, transcription factors, and extracellular matrix components. Gene ontology approaches identified 892 differentially expressed genes not previously identified during the initiation of chondrogenesis. These included several Bmp, Gdf, Wnt, Sox and Fox family members.

Conclusion: These data represent the first global gene expression profiling analysis of chondrogenic tissues during in vivo development. They identify genes for further study on their functional roles in chondrogenesis, and provide a comprehensive and important resource for future studies on cartilage development and disease. 


\section{Background}

Developing a detailed knowledge of the developmental pathways involved in limb skeletogenesis is important for understanding skeletal abnormalities and disease processes, and for further unravelling the fundamental regulatory pathways that control development. The development of the vertebrate limb skeleton is initiated when multipotent mesenchymal cells in the limb bud aggregate to form mesenchymal condensations which prefigure the skeletal elements. Cells within the pre-chondrogenic condensation up-regulate cell adhesion mechanisms and begin to synthesize specific extracellular matrix molecules, and the condensations expand through a combination of proliferation and recruitment of surrounding mesenchyme. The generation of these condensations creates an environment which is conducive to chondrogenic differentiation $[1,2]$. As the cells differentiate into chondrocytes, they synthesize a framework of cartilage matrix, known as an anlage, in the approximate shape of the future bone. Chondrocytes in the centre of the anlage proceed through a series of discrete developmental stages that include proliferation, maturation and hypertrophy [1,3-7]. The hypertrophic cartilage is first calcified and then, following vascular invasion, replaced by primary bone that is subsequently remodelled to form secondary bone. This process radiates outwards from the centre of the anlage with the development of highly ordered growth plates that separate the cartilaginous epiphyses from the bony diaphysis. Later in development, secondary centres of ossification develop within the epiphyses and, with subsequent fusion of the ossification centres during puberty, endochondral ossification and bone growth ceases.

The regulatory network that controls early chondrogenesis is incompletely understood although several key components have been characterized. Prior to pre-chondrogenic mesenchymal condensation in the developing vertebrate limb bud, Bmp expression is upregulated in the mesenchyme flanking the anterior and posterior margins and in the presumptive interdigital mesenchyme, in a manner consistent with a role for these genes in limb patterning and in initiating chondrogenesis and skeletal development $[8,9]$. Furthermore, viral misexpression of the Bmpantagonist, Noggin, in the developing limb during embryogenesis [10] and targeted over-expression of Noggin in chondroprogenitor cells [11], both result in complete blockage of mesenchymal condensation and chondrogenesis, proving the requirement for Bmp signalling in the initiation of chondrogenesis. Bmp signalling serves multiple purposes during the initiation of chondrogenesis; it may contribute to the recruitment of cells to the condensation, the proliferation of cells within the condensation, as well as regulating the expression of genes involved in driving the differentiation of condensed mesenchyme [2].
In addition to the roles of Bmps in skeletal development per se, Bmp, along with Bmp antagonists (eg., chordin and noggin) and members of the Gdf (growth and differentiation factor) family are involved in controlling the cartilage condensations that develop into the synovial joint. The Fof family of growth factors and their receptors also play an important role in chondrocyte differentiation, possibly by limiting chondrocyte proliferation, since activating mutations in FGFR3 cause achondroplasia and thanatophoric dysplasia and Fgfr3-deficient mice have an enlarged growth plate. A critical component of chondrocyte lineage specification is Sox9 (a high mobility group transcription factor), which exerts its influence over chondrogenesis, in part, by regulating the expression of multiple cartilage-specific proteins including Col2a1 [12]. The influence of Sox 9 on chondrogenesis is largely dependent upon Sox 5 and Sox6, with which it co-regulates the chondrogenic program [13].

In addition to the signalling cascades, the extracellular matrix (ECM) plays a fundamental role in morphogenesis and development by regulating cell differentiation, proliferation, adhesion, and migration, and by modulating growth factor bioavailability. Mesenchymal condensations are characterized by the expression of a specific ECM, components of which include fibronectin [14], tenascin C [15], NG2 proteoglycan [16], syndecan [17], and chondroitin-sulphate proteoglycans [18]. The ECM has important roles in promoting the condensation and differentiation of mesenchymal cells [2]. As the cells differentiate into chondrocytes they express specific ECM components with unique functional and biological characteristics which are critical for cartilage structure and function $[19,20]$. The predominant, well-characterized cartilage matrix components are the proteoglycan, aggrecan, and members of the collagen protein family. Collagen II is a major homotrimeric collagen expressed throughout the cartilage that interacts specifically with other minor collagens such as IX and XI to modulate interfibrillar interactions between the heterotypic collagen fibrils [21]. Mutations in many of these collagen genes have been identified in human chondrodysplasias and in mouse models $[7,22,23]$. Collagen VI is a microfibrillar collagen which is found localized in the pericellular space around chondrocytes in epiphyseal cartilage.

Cartilage contains many other proteins, some of which have been well-characterized and whose roles in cartilage structure and function have been elucidated [19,24-27]. Some of the best characterized components are the small leucine-rich proteins (SLRPs), such as decorin, fibromodulin, lumican and biglycan which interact with collagen fibrils and influence collagen fibrillar architecture and function. These SLRPs have growth factor binding properties that may have profound influences on cartilage cell 
proliferation. Cartilage oligomeric matrix protein also binds collagen fibrils and may also mediate cell-matrix interactions. Other proteins include chondroadherin and thrombospondin which have cell-matrix binding properties; tenascins, osteonectin and members of the matrilin family, matrilins 1 and 3, that are thought to form interacting assemblies integrating the collagen and proteoglycan networks.

While a number of the chondrogenesis genes have been extensively characterized, the full spectrum of components involved in regulating chondrogenesis during limb development has yet to be determined. However, with the advent of high quality whole genome microarrays we now have the unique opportunity to determine the comprehensive gene expression pattern of processes such as chondrogenesis, to define novel components and further unravel the complex developmental processes involved. The application of such expression profiling approaches to cartilage formation in vivo has thus far been restricted by the technical challenge of obtaining high quality RNA from the target tissues. Consequently, expression studies to date have been conducted on either whole mouse limbs $[28,29]$ or on in vitro models of chondrogenesis [30-32]. While these studies have been useful in identifying some chondrogenic genes, they suffer from the limitations of analysing heterogeneous tissues or the complex gene expression consequences that may result from in vitro culture.

In this study we report the first global gene expression profiling analysis of the transition of pre-condensed mesenchymal cells into mesenchymal condensations, and their subsequent differentiation into chondrocytes, using tissue microdissected from in vivo mouse limb buds. By comparison of the gene expression profiles of cartilage pre-condensation tissue at $11.5 \mathrm{dpc}$, mesenchymal condensations at $12.5 \mathrm{dpc}$, and differentiated cartilage tissue at $13.5 \mathrm{dpc}$, we were able to identify the candidate gene cohorts involved in the initiation of chondrogenesis and in the early development of cartilage anlagen. As well as identifying novel genes that may be critical in the regulation and maintenance of chondrogenesis, our data allowed us to present the first comprehensive expression analysis of the known developmentally important gene families during in vivo chondrogenesis during mouse limb skeletal development. These data provide confirmation of the role of many members of these key gene families, and also implicate other members of these, and other gene families in chondrogenesis for the first time.

\section{Results and discussion}

Microdissected samples from I I.5 dpc to I3.5 dpc

encompass the initial developmental steps of

\section{chondrogenesis}

Prior to microarray analysis, the differential expression of selected key markers of mesenchymal condensation and chondrogenesis was assayed by semi-quantitative PCR to confirm the developmental stage represented by each microdissected tissue sample (Fig. 1). The genes chosen for semi-quantitative PCR analysis were $\mathrm{N}$-cadherin $(\mathrm{Ncad})$, aggrecan $(\mathrm{Agc1})$, collagen II (Col2a1), cartilage oligomeric matrix protein (Comp), cartilage link protein (Hapln1, hyaluronan and proteoglycan link protein 1) and the gene encoding S12 ribosomal RNA, which was included as a loading standard. Ncad is a cell-cell adhesion molecule whose role in mesenchymal condensation during limb development has been well characterized [33]. Expression of aggrecan, collagen II, Comp and cartilage link protein is indicative of cartilage formation [34].

Semi-quantitative PCR demonstrated Ncad transcripts were abundant at $11.5 \mathrm{dpc}$, immediately prior to the commencement of mesenchymal condensation. A marked decrease in Ncad transcription was observed by $12.5 \mathrm{dpc}$ and this low level of expression was maintained until 13.5 dpc. Agc1 and Col2a1 were present at low levels in 11.5 dpc embryos, well before the deposition of significant extracellular matrix. Transcription of both these markers increased by $12.5 \mathrm{dpc}$, and they became highly abundant by $13.5 \mathrm{dpc}$. Neither Comp nor Hapln1 transcripts were present at levels detectable by semi-quantitative RT-PCR

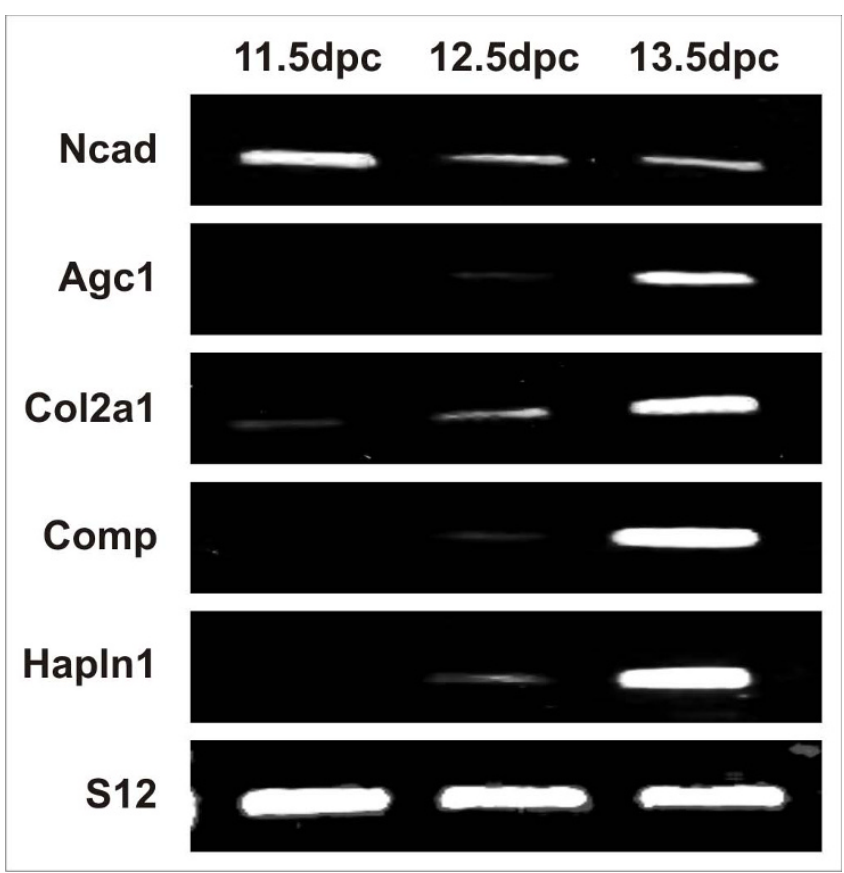

Figure I

Semi-quantitative PCR analysis of cartilage specific gene expression in microdissected limb cartilage condensations. Agarose gel electrophoresis of PCR products generated by primers specific for $\mathrm{N}$-cadherin (Ncad), aggrecan $(\mathrm{Agcl})$, procollagen II alpha I (Col2al), cartilage link protein (Hapln I; hyaluronan and proteoglycan link protein I), and ribosomal protein $\mathrm{SI} 2$ (SI2). 
at $11.5 \mathrm{dpc}$. Low-level transcription of Comp and Hapln 1 was observed at $12.5 \mathrm{dpc}$, and increased dramatically by $13.5 \mathrm{dpc}$. These data provided clear evidence that the microdissected regions of the limb buds represented mesenchymal condensations undergoing the in vivo transition from undifferentiated chondroprogenitor cells to differentiated chondrocytes.

\section{Whole genome expression profiling}

As an overall representation of the microarray hybridizations, M/A scatter plots were generated for each time point comparison in which the mean signal intensity (Average $\log _{2}$ Intensity; A) for each microarray probe was plotted against the relative fold difference for that probe (Fig. 2). Negative control probes, which are not complementary to any mouse mRNA sequences, have been included on these microarrays by the manufacturer to gauge non-specific, background fluorescence. Using these probes, it was determined that an average $\log _{2}$ intensity of less than or equal to six represented background fluorescence (indicated by dashed orange line in Fig. 2).

Scatter plot comparisons were generated by subtracting the signal intensity of $11.5 \mathrm{dpc}$ from $12.5 \mathrm{dpc}$ (Fig. 2A), $12.5 \mathrm{dpc}$ from $13.5 \mathrm{dpc}$ (Fig. 2B), and $11.5 \mathrm{dpc}$ from 13.5 dpc (Fig. 2C). By plotting the data in this manner for each of the three comparisons, genes which were expressed in equal relative abundance between time points were plotted close to zero on the relative fold difference (vertical; $\mathrm{M})$ axis. Genes which were more highly expressed at the later time points were plotted on the positive scale of the relative fold difference axis (red). Conversely, genes which were more highly expressed at the earlier time points were plotted on the negative scale of the relative fold difference axis (green). The data-points for selected markers of mesenchymal condensation ( $\mathrm{Ncad}$, growth differentiation factor $5-G d f 5$, and protocadherin $8-P c d h 8)$, chondrogenesis (Agc1, Col2a1, Comp and matrilin 1 Matn1), myogenesis (myogenic differentiation 1 Myod1), and chondrocyte hypertrophy (procollagen type 10 alpha 1 - Col10a1), as well as a house keeping gene as an internal standard (hydroxymethylbilane synthase $\mathrm{Hmbs}$ ) have been highlighted in each scatter plot. It can be seen in each of the plots in Figure 2 that the selected markers of chondrogenesis were found to be expressed more highly in the later time point, while markers of mesenchymal condensation were found to be expressed more highly at the earlier time point. Consistently, the average $\log _{2}$ intensity for Col10a1 was found to be below six, confirming that Col10a1, a marker of cartilage hypertrophy, was not expressed in any of the microdissected tissues and that the cartilage anlagen microdissected at $13.5 \mathrm{dpc}$ were pre-hypertrophic. For Myod1, the average $\log _{2}$ intensity was found to be very close to background level and the relative fold difference close to zero, indicating negligible
Myod1 expression in these tissues, and suggesting that there was no significant contamination of the microdissected tissues by myogenic precursors.

In order to generate global representations of biological processes driving chondrogenesis, the microarray data were mined using OntoExpress gene ontology software. Genes up-regulated or down-regulated between $11.5 \mathrm{dpc}$ to $13.5 \mathrm{dpc}$ by at least three-fold, and for which an average $\log _{2}$ intensity $>6$ was detected, were classified according to biological process (see Additional file 1). By this method, 931 significantly differentially expressed genes were identified - 380 down-regulated genes and 551 upregulated genes. These genes are shown in Additional file 2. The full microarray dataset are available from the Gene Expression Omnibus (GEO) database repository http:// www.ncbi.nlm.nih.gov/geo.

\section{Validation of microarray data}

Three approaches were taken to validate the microarray dataset generated in the present study - quantitative PCR (qPCR), in situ hybridization, and an extensive comparison of the gene expression dataset generated in this study with expression and function data pertaining to the same genes in the scientific literature. To provide microarray validation over a wide range of gene expression levels we performed qPCR on genes expressed at high levels by chondrocytes, such as extracellular matrix components (eg. Col2a1), and also those expressed at much lower levels, such as transcription factors (eg. Foxa3). In addition, array validation was performed for representative genes from the developmentally important gene families; adhesion molecules, secreted signalling molecules, transcription factors and extracellular matrix molecules.

\section{Quantitative PCR}

Using unmodified cRNA samples amplified in parallel to those cRNA samples generated for the microarray analyses, GPCR was performed on selected genes as a technical validation for the microarray data. QPCR was performed on Agc1 (Fig. 3A), Bmp8a (Fig. 3B), Col2a1 (Fig. 3C), Fgfr4 (Fig. 3D), Foxa3 (Fig. 3E), Gdf5 (Fig. 3F), Klf2 (Fig. 3G), Klf4 (Fig. 3H), Lepre1 (Fig. 3I), Ncad (Fig. 3J), Sox11 (Fig. 3K), and Trpv4 (Fig. 3L). For each marker, a close correlation was observed between the pattern of differential gene expression determined using either technique, with highest expression for markers of mesenchymal condensation seen between $11.5 \mathrm{dpc}$ and $12.5 \mathrm{dpc}$, and highest expression for markers of chondrogenesis seen at $13.5 \mathrm{dpc}$.

\section{In situ hybridization}

In order to validate the microarray data further with independent, biological replicates, in situ hybridization was performed on sagittal sections from $11.5 \mathrm{dpc}, 12.5 \mathrm{dpc}$, and $13.5 \mathrm{dpc}$ mouse hind limb buds using probes for 


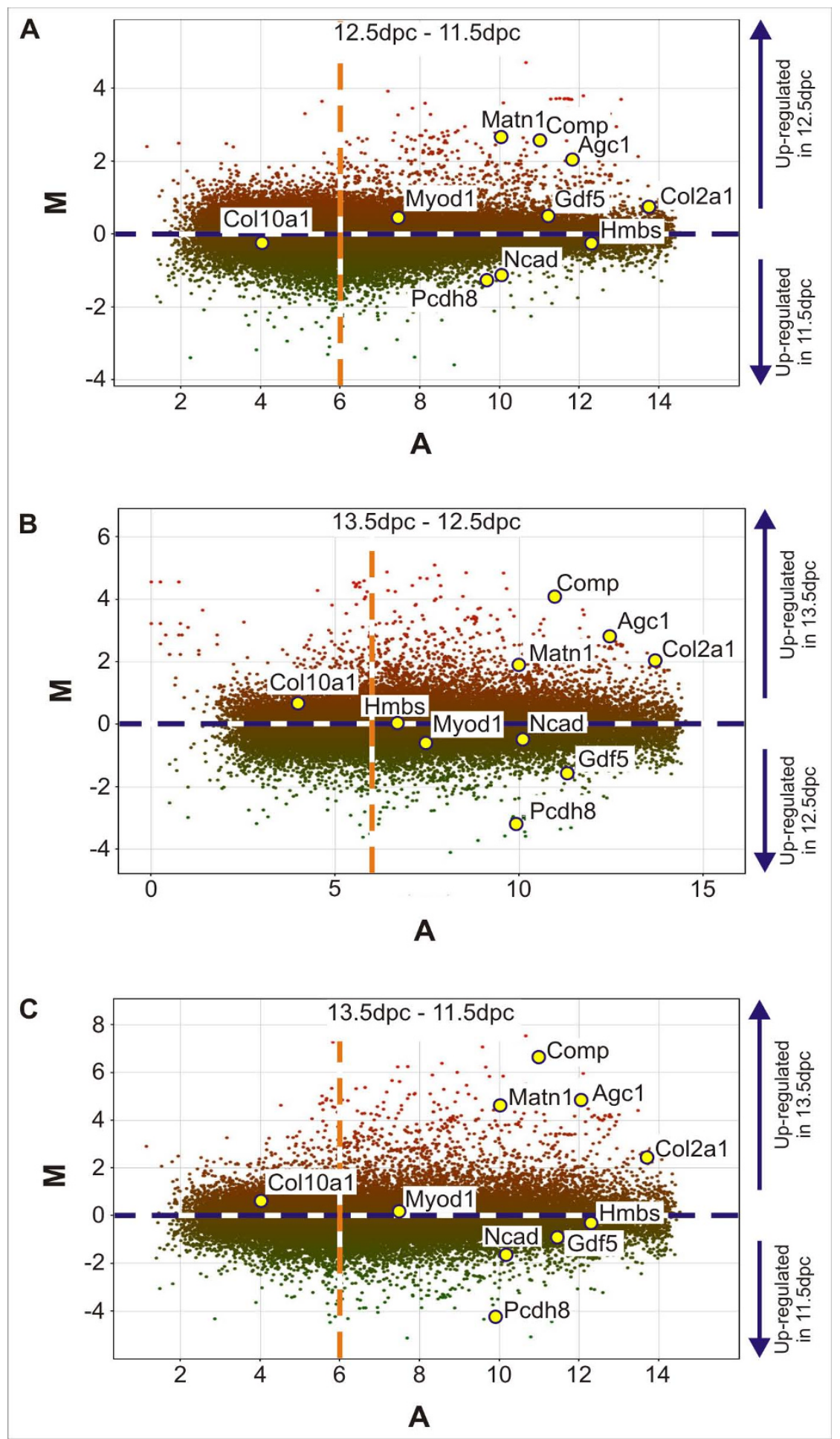

Figure 2

Mouse whole genome microarray M/A scatter plots. A) I2.5 dpc - II I.5 dpc. B) I3.5 dpc - I2.5 dpc. C) I3.5 dpc - II I.5 dpc. $M$ represents the log ratio of the two dyes and A represents the average $\log _{2}$ intensity. Yellow spots with blue outline indicate the expression data for selected genes. The dashed blue line indicates a fold difference of zero representing no differential expression between the two samples analysed. The dashed orange line indicates a average Log $_{2}$ intensity (A) of 6 , representing the background signal intensity. 


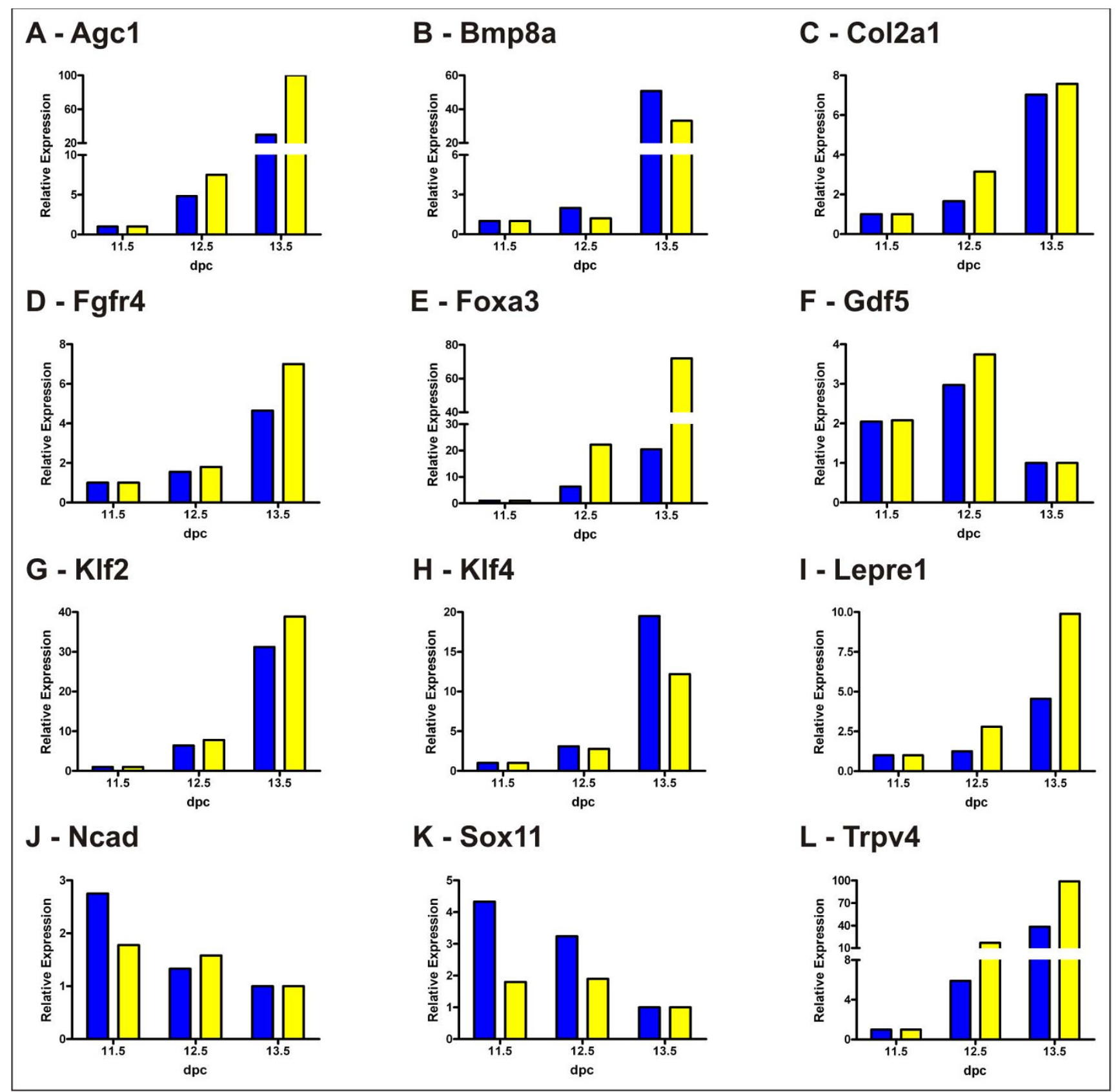

Figure 3

Comparison of differential expression profiles of selected genes analysed by quantitative real time PCR or microarrays. Expression was analyzed in amplified mRNA by quantitative real time PCR analysis (qPCR; yellow bars) or microarray analysis (blue bars) for A) aggrecan (Agcl); B), Bmp8a; C), Col2al; D), Fgfr4; E), Foxa3, F), Gdf5; G), KIf2, H), Klf4; I), Lepre I; J), Ncad; K), Sox I I; L) Trpv4. qPCR experiments were performed in triplicate.

Sox11 (Fig. 4A-C), Pcdh8 (Fig. 4D-F), Lepre1 (Fig. 4G-I), and Trpv4 (Fig. 4J-L). In each case, the gene expression detected by in situ hybridization corroborated the expression profiles generated by microarray and clarified the expression of these genes in the limb bud beyond the microdissected areas.
Strong expression of Sox 11 was observed throughout the limb bud and also in the adjacent somites at $11.5 \mathrm{dpc}$ (Fig. 4A). At $12.5 \mathrm{dpc}$, expression of Sox 11 was generally weaker than at $11.5 \mathrm{dpc}$, and found to be most highly expressed in the interdigital mesenchyme distally, and localized to the tibial and fibular mesenchymal condensa- 


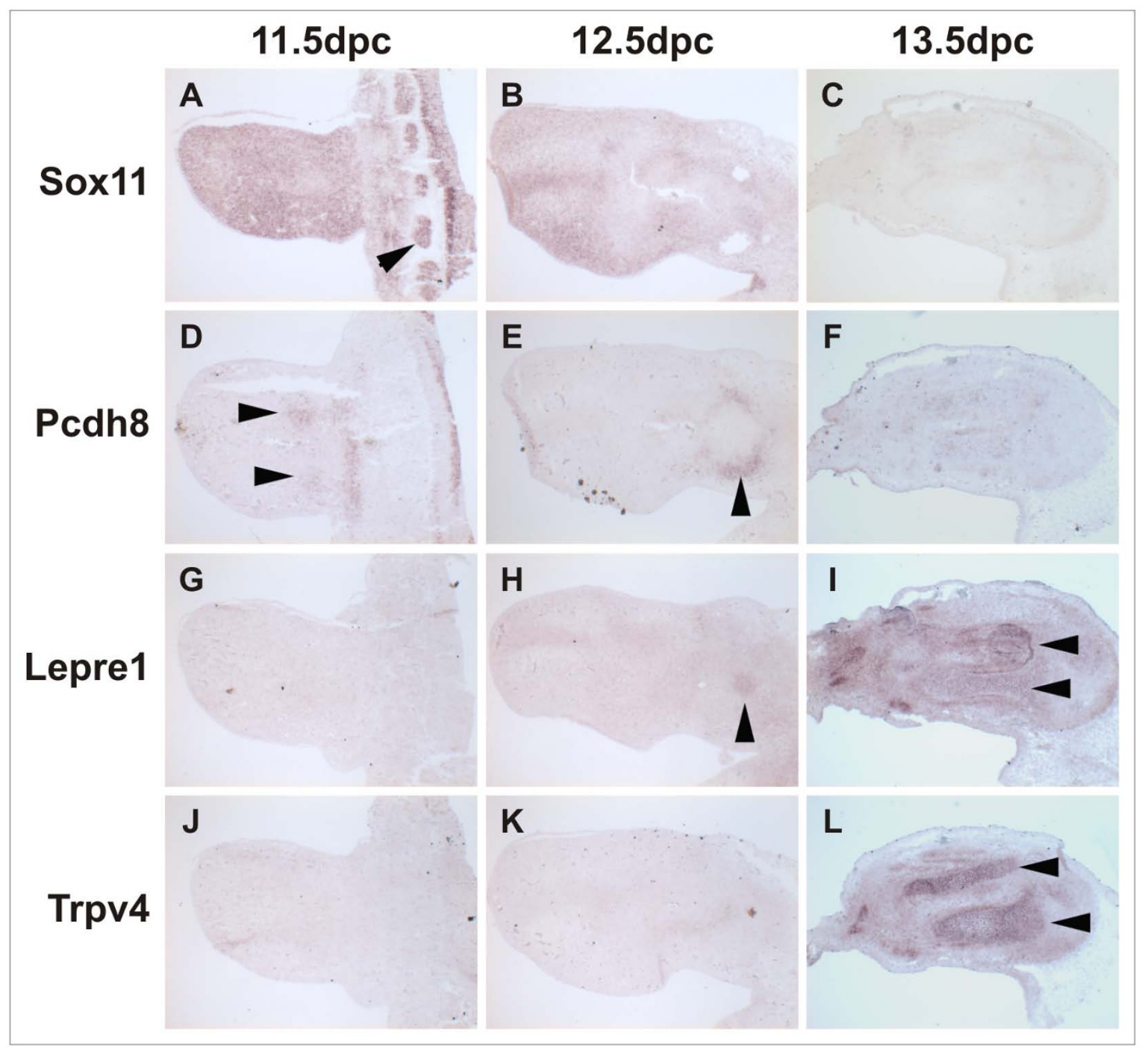

\section{Figure 4}

In situ hybridization analysis of Sox I I, Pcdh8, Lepre I and Trpv4 in embryonic mouse hindlimbs. Antisense probes were used to determine the level and distribution of mRNA for each gene. Expression of Sox I I is widespread throughout the limb bud and somites (arrowhead) at EII .5 but declines in level by EI2.5 and becomes undetectable by EI3.5. Pcdh8 is expressed within the pre-condensations of the tibia and fibula (arrowheads) at EII.5 but is downregulated by the condensation phase at EI2.5. At this stage expression is detected in the tissue surrounding the femoral condensation (arrowhead) but declines to background levels by EI 3.5. Leprecan I is not detectable at EI I.5 but becomes visible in the femoral condensation at EI2.5 (arrowhead) and is upregulated within the tibia and fibula at EI 3.5 (arrowheads). Trpv4 is not detectable within the limb buds at EII.5 or EI2.5 but is strongly upregulated in the tibia and fibula at EI3.5 (arrowheads). Distal is to the left in all images.

tions, as well as the anterior and posterior margins of the limb bud proximally (Fig. 4B). At 13.5 dpc, Sox11 expression was very weak distally and absent from the tibia and fibula (Fig. 4C). This pattern of Sox11 expression agrees with the expression profiles generated by microarray and
qPCR, where Sox11 was found to be down-regulated during development of the tibial and fibular cartilage anlagen. Similarly, Pcdh8 also exhibited declining expression levels from $11.5 \mathrm{dpc}-13.5 \mathrm{dpc}$. At $11.5 \mathrm{dpc}$, Pcdh8 expression was detected in the precondensed tibial and fibular 
mesenchyme (Fig. 4D) but was absent from the distal limb at E12.5 (Fig 4E). In contrast, Pcdh8 expression at E12.5 was predominantly detected surrounding the femoral condensation (Fig 4E) but became undetectable within the limb by E13.5 (Fig 4F). Thus, as with the expression profile generated by microarray for $P c d h 8$, in situ hybridization confirmed that expression of Pcdh8 is down-regulated in the areas of tibial and fibular development.

Lepre1 expression was not detectable in the limb bud at $11.5 \mathrm{dpc}$ (Fig. 4G). By $12.5 \mathrm{dpc}$, weak expression of Lepre1 was observed in the femoral, tibial, and fibular prechondrogenic mesenchymal condensations (Fig. 4H). Lepre1 was found to be highly expressed throughout the cartilage anlagen, though not in the perichondrium, at $13.5 \mathrm{dpc}$ (Fig 4I). Similar results were obtained for Trpv4, which was not detectable at either $11.5 \mathrm{dpc}$ (Fig. 4J) or $12.5 \mathrm{dpc}$ (Fig. 4K), but which was highly expressed throughout the cartilage anlagen at 13.5 dpc (Fig. 4L).

The in situ hybridization data presented here for Sox11, Pcdh8, Lepre1, and Trpv4 are consistent with the expression profiles generated for these genes in the present study by microarray analysis and qPCR. In so doing, they reinforce the utility of the present microarray dataset for providing accurate information about the expression profiles of developing chondrogenic tissues in vivo.

\section{Comparative literature analysis}

As a third approach to validating the microarray data generated in the present study, an extensive survey of the scientific literature was carried out in order to compare our gene expression dataset with expression and function data pertaining to the same genes examined in previous studies (see Additional file 3). For the 50 genes surveyed, we found that our expression profiles were highly consistent with previously published data, emphasising the value of the present dataset as a tool for further understanding the dynamic gene expression environment controlling in vivo chondrogenesis.

\section{Differential expression of gene families during chondrogenesis \\ Adhesion Molecules}

Consistent with their roles in mediating cell-cell contacts, it was found that most protocadherins (Fig. 5A) and cadherins (Fig. 5B) were down-regulated from $11.5 \mathrm{dpc}-$ immediately prior to the commencement of mesenchymal condensation, to $13.5 \mathrm{dpc}$ - when cartilage anlagen have formed. The protocadherins are a family of type I membrane proteins belonging to the cadherin superfamily which are characterized by multiple extracellular cadherin domains and unique intracellular domains bridged by a single membrane-spanning segment [35]. The function of the protocadherins is unclear and while they may function in cell-cell adhesion, they are also likely to have a role in intercellular signalling. Of the differentially regulated protocadherin ( $P c d h)$ genes (Fig. 5A), the most highly down-regulated were Pcdh 8 and Pcdh10. Pcdh9 and Pcdh18 were also found to be significantly down-regulated, but more highly expressed than Pcdh 8 and Pcdh10. None of the protocadherins were found to be significantly up-regulated during in vivo chondrogenesis. To date, none of the protocadherins have been implicated in chondrogenesis, and Pcdh 8 is the only protocadherin previously found to be expressed during limb development [36].

The cadherin genes encode membrane-spanning proteins characterized by multiple cadherin domains which mediate calcium-dependent homophilic adhesion between neighbouring cells in a wide range of developmental processes [37]. Among the cadherin (Cdh) genes (Fig. 5B), $\mathrm{Cdh} 8$ and $\mathrm{Cdh} 4$ were found to exhibit the highest differential expression. Notably, expression of both of these genes peaked during mesenchymal condensation at $12.5 \mathrm{dpc}$, before being down-regulated in the cartilage anlagen at $13.5 \mathrm{dpc}$. Cdh11, although not significantly differentially expressed, was found to be very highly expressed throughout in vivo chondrogenesis. Cdh11 has recently been shown to be a discriminative factor between articular and growth plate cartilage chondrocytes [38]. N-cadherin (Ncad, Cdh2) was found to be very highly expressed and was down-regulated by almost 3-fold from $11.5 \mathrm{dpc}$ to $13.5 \mathrm{dpc}$, consistent with its characterized role in condensation.

Ncam was highly expressed throughout in vivo chondrogenesis, and marginally up-regulated between $11.5 \mathrm{dpc}$ and $13.5 \mathrm{dpc}$. It is recognized that in the context of chondrogenesis, cell-cell adhesion is most likely mediated primarily by Cdh2 [33] and Cdh11 - in conjunction with other factors such as Ncam1 [39]. This view is supported by the findings presented here, in which Ncam1, along with $C d h 2$ and $C d h 11$ were highly expressed during the initiation of chondrogenesis, while other cadherins were expressed at a much lower level (Fig. 5B).

\section{Secreted signalling molecules}

The relative differential expression of genes belonging to major families of signalling molecules secreted during in vivo chondrogenesis are shown (Fig. 5C-F). Included in this category are the bone morphogenetic protein $(B m p)$ family (Fig. 5C), the growth differentiation factor (Gdf) family (Fig. 5D), the wingless-related MMTV integration site (Wnt) family (Fig. 5E), and the fibroblast growth factor family (Fig. 5F). The chondroinductive potential of the Bmp family has been extensively analysed, and it is known that chondrogenesis may be induced by the activity of Bmp2 [40], Bmp4 [41], Bmp5 [42], Bmp6 [43], and 


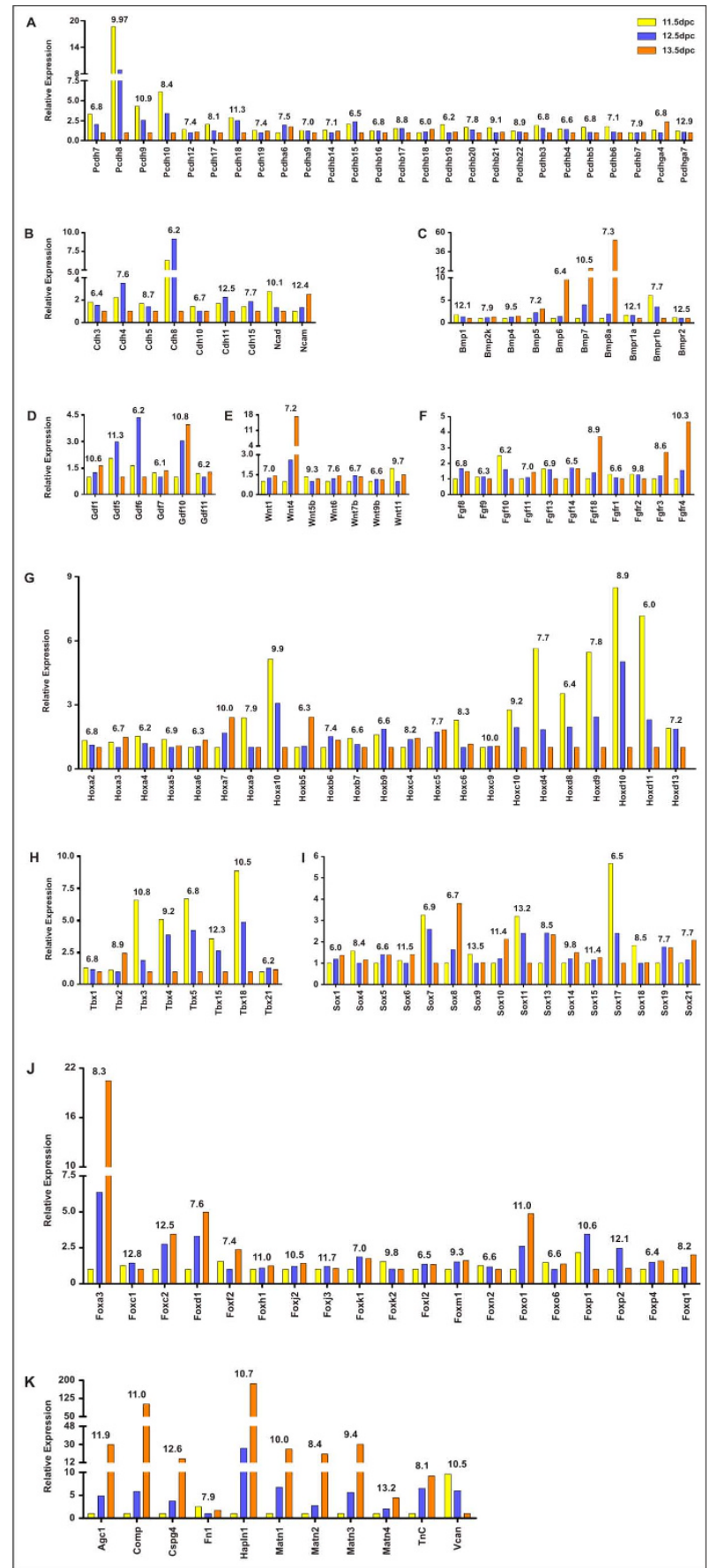

\section{Figure 5}

Microarray differential expression profiles of selected developmental gene families. A), protocadherins (Pcdh); B), cadherins $(\mathrm{Cdh})$; C), bone morphogenetic proteins and bone morphogenetic protein receptors (Bmp and Bmpr); $\mathbf{D})$, growth differentiation factors (Gdf); E), Wnt family, (Wnt); F), fibroblast growth factors and fibroblast growth factor receptors (Fgf and Fgfr); G), homeobox transcription factors (Hox); H), T-box transcription factors (Tbx); I), Sry-like homeobox transcription factors (Sox); J), forkhead/winged helix box transcription factors (Fox); K), selected non-collagenous extracellular matrix molecules. Yellow bars indicate relative expression at II.5 dpc. Blue bars indicate relative expression at I2.5 dpc. Orange bars indicate relative expression at $13.5 \mathrm{dpc}$. For each gene, the time point at which the relative expression was lowest was defined as one, and this was used to calculate the relative expression at the remaining time points. Numbers above each gene denote average $\log _{2}$ intensity (A) for that gene. 
Bmp7 [44]. Moreover, expression of Bmp8a in developing long bones has been demonstrated, and it is known to map to the mouse achondroplasia locus [45], suggesting that it too may be an important regulator of chondrogenesis. Consistent with these observations, $B m p 8 a$ was found to be the most highly differentially expressed Bmp gene, up-regulated over 50-fold between $11.5 \mathrm{dpc}$ and 13.5 dpc. $B m p 6$ and $B m p 7$ were also highly differentially expressed. $B m p 7$ was more highly expressed than $B m p 8 a$, while overall expression of $B m p 6$ was low. Although not highly differentially expressed, $B m p 1$ was found, like $B m p 7$, to be very highly expressed. Expression of $B m p 2$ was found to be absent from this assay of in vivo chondrogenesis.

It is known that the Gdf family contributes to the regulation of chondrogenesis. Gdf5 may induce chondrogenesis in vitro [46], and it has been used to induce ectopic chondrogenesis in vivo, in part by stimulating expression of another marker of chondrogenesis, transcription factor Barx2 [47]. Moreover, single gene knock-outs of Gdf5 and GdfG resulted in defects in multiple elements of the appendicular and craniofacial skeletons, while a more severe skeletal phenotype was observed for the Gdf5/GdfG double knock-out mouse [48]. These findings are consistent with the extremely similar differential expression profiles determined for Gdf5 and GdfG in the present study, in which the expression of both genes peaked significantly at $12.5 \mathrm{dpc}$ (Fig. 5D). By contrast, little is known of the role of Gdf10 in chondrogenesis. Indeed, the only report to date in which Gdf10 has been implicated in skeletal biology concerned its expression during bone repair in a model of fracture healing [49]. The steady up-regulation of Gdf10 observed between $11.5 \mathrm{dpc}$ and $13.5 \mathrm{dpc}$ in the present study however, suggests that Gdf10 may play an important role in mesenchymal condensation and chondrocyte maturation. Overall, six Gdf genes were expressed during in vivo chondrogenesis (Fig. 5D). Gdf6 was found to be most highly differentially expressed, peaking at $12.5 \mathrm{dpc}$, although overall expression of Gdf6 was very low. Both Gdf5 and Gdf10 were strongly expressed, and highly differentially expressed. Gdf1, although not highly differentially expressed, was found to be expressed strongly throughout in vivo chondrogenesis.

It is well established that Wnt proteins mediate important signalling pathways at various stages of chondrogenesis. Accordingly, Wnt gene expression in vivo is found to be spatially and temporally restricted within the developing cartilage anlage. Wnt4 expression is localized to the developing joints, Wnt5a to the perichondrium, and Wnt5b to the perichondrium and prehypertrophic chondrocytes $[50,51]$. Moreover, functional work presented in the same studies demonstrated that Wnt 4 promotes chondrocyte hypertrophy, while Wnt5a and Wnt5b operate conversely, by impeding terminal chondrocyte differentiation. Thus, while the data generated by microarray analysis here provides valuable information about relative expression levels, the authors recognise that it cannot provide information regarding the spatial distribution of transcripts within the microdissected tissues. Among the Wnt family, only Wnt11 and $W n t 5 b$ were strongly expressed, and only one Wnt (Wnt4) was found to be highly differentially expressed and dramatically up-regulated between $12.5 \mathrm{dpc}$ and $13.5 \mathrm{dpc}$ (Fig. 5E). Conversely, frizzledrelated protein $(F r z b)$, a Wnt antagonist, was found to be strongly expressed, and down-regulated between $11.5 \mathrm{dpc}$ and $13.5 \mathrm{dpc}$ (see Additional file 2).

Despite their prominent role in controlling aspects of endochondral bone growth, little is known about the expression or function of Fgf ligands and Fgf receptors within mesenchymal condensations and subsequent cartilage anlagen [52]. Recent work however points to a role for Fgf18 in regulating chondrocyte proliferation and hypertrophy during the earliest stages of chondrogenesis (expression being detected as early as $14.5 \mathrm{dpc}$ ) through interaction with Fgfr3 [53]. Our differential expression data (Fig. 5F) support and extend these findings by revealing significant up-regulation of both $\mathrm{Fgfl} 18$ and $\mathrm{Fgfr} 3$ between $11.5 \mathrm{dpc}$ and $13.5 \mathrm{dpc}$, and by clarifying the differential expression patterns of $F g f$ ligands and $F g f$ receptors within chondrogenic tissue in vivo. Of considerable interest was the finding that Fgfr4 expression is significantly up-regulated between $11.5 \mathrm{dpc}$ and $13.5 \mathrm{dpc}$. Fgfr 4 has not previously been associated with chondrogenesis, although it is known to mediate early events in the signalling cascade regulating skeletal muscle development in the developing limb [54]. The Fgfr4 differential expression data presented here imply that in addition to the role of Fgf4 in myogenesis, it may also have a role in chondrogenesis.

\section{Transcription factors}

The first families of transcription factors considered here are the homeo box (Hox) genes (Fig. 5G). A large group of genes comprised of four gene clusters, the Hox genes were mostly found to be down-regulated from $11.5 \mathrm{dpc}$ to 13.5 $\mathrm{dpc}$, although the opposite trend was observed for some Hox genes. Only three members (Hoxa7, Hoxa10, and Hoxa11) of the Hoxa gene cluster were strongly expressed. The most highly differentially expressed of these was Hoxa10. Hoxa 7 and Hoxa 11 were more strongly expressed than Hoxa10 however, although neither was significantly differentially expressed. Four Hoxb genes were weakly expressed during in vivo chondrogenesis, and none of them were highly differentially expressed. Only one Hoxc gene (Hoxc10) was highly differentially expressed during in vivo chondrogenesis, down-regulated by almost 3-fold from $11.5 \mathrm{dpc}$ to $13.5 \mathrm{dpc}$. None of the other Hoxc genes 
were significantly differentially expressed, although the expression level of Hoxc9 was found to be very high throughout the time course. Most of the Hoxd gene cluster were very weakly expressed. The most highly down-regulated Hoxd genes were generally the more $3^{\prime}$ members of the cluster (Hoxd9, Hoxd10, Hoxd11, and Hoxd13). While Hox genes have established roles in pattern formation, they may play additional roles in chondrogenesis. The overall down-regulation of the more highly expressed members of the Hox family suggests that Hox gene silencing may be required for the progression of cartilage formation. Transgenic mouse data showing that the persistent expression of Hoxa2 in cells entering chondrogenesis impairs cartilage development and causes chondrodysplasia [55], supports this inhibitory role for at least a subset of Hox genes. A further early role for Hox genes in regulating the expression of the key chondrogenic transcription factor, Sox9, has been shown in recent experiments [56].

Interestingly, while many Hox genes were found to be down-regulated in chondrogenic tissue from $11.5 \mathrm{dpc}$ to $13.5 \mathrm{dpc}$ in the present study, three Hox genes (Hoxa7, Hoxb5, and Hoxc5) were up-regulated during this time by close to or greater than two-fold. This is the first time that vertebrate limb expression data has been published for Hoxa7, Hoxb5, and Hoxc5.

Eight T-box $(T b x)$ genes were expressed during in vivo chondrogenesis (Fig. 5H). Of these Tbx15, Tbx3 and $T b x 18$, were all strongly expressed and highly down-regulated from $11.5 \mathrm{dpc}$ to $13.5 \mathrm{dpc}$.

Expression of 16 Sry-box (Sox) genes was detected during in vivo chondrogenesis (Fig. 5I). Of these, four were found to be highly expressed although none of these four genes were significantly differentially expressed. Among these genes were Sox9 and Sox6. Moderate expression levels were detected for five Sox genes and of these, only Sox 8 was significantly differentially expressed, up-regulated by almost 4 -fold between $11.5 \mathrm{dpc}$ and $13.5 \mathrm{dpc}$. Seven Sox genes were found to be expressed weakly during in vivo chondrogenesis. Expression data generated in the present study are consistent with the importance of Sox9 throughout chondrogenesis $[57,58]$. Sox9 was not highly differentially expressed from $11.5 \mathrm{dpc}$ to $13.5 \mathrm{dpc}$ but its average $\log _{2}$ intensity was found to be extremely high, indicating ubiquitously high expression of Sox 9 throughout the transition from pre-chondrogenic mesenchymal cell to fully differentiated chondrocyte. It is known that Sox9 exerts its influence over chondrogenesis, in part, by regulating the expression of multiple prominent components of the cartilage matrix including the quintessential chondrocyte marker, Col2a1 [12]. This transcriptional activity was found to be largely dependent upon the combined activity of a long form of Sox5 (L-Sox5), and Sox6 [59]. In the present study, Sox6 expression closely resembles that of Sox9 in that although it was not found to be highly differentially expressed throughout chondrogenesis, its absolute expression level (average $\log _{2}$ intensity) was found to be very high.

Interestingly Sox 5 expression was quite low in the present study (Fig. 5I). It is possible that this result does not accurately reflect the abundance of Sox 5 transcripts because of technical limitations with array design. The single probe for Sox 5 on the microarray is located 1445 bp upstream of the 3 '-end of the mouse Sox 5 coding sequence, and since the amplified RNA used to interrogate to array has an inherent 3' bias, it is likely that this results in an inability to hybridize efficiently.

Our results also demonstrate that additional Sox genes, Sox4, Sox8, Sox10, Sox11 and Sox13 participate in chondrogenesis in vivo. Previous studies have shown Sox4 expression localized to diaphyseal hypertrophic chondrocytes during the commencement of long bone ossification, and later in the hypertrophic chondrocytes of the embryonic growth plate [60], as well as along the posterior margin, and proximally on the anterior margin of chicken limb buds at a stage equivalent to mouse hindlimb $11.5 \mathrm{dpc}$ [61]. Expression of Sox8 and Sox10 has also been noted previously in limb development, occurring, like that of Sox5, Sox6, and Sox9, in a manner which essentially prefigures the developing skeleton [62]. Moreover, in the same study it was noted that each of these genes was up-regulated in ectopic cartilages in response to Bmp7, implying roles for Sox8 and Sox10 in chondrogenesis. The highly similar expression patterns detected for Sox8 and Sox10 here suggest that these genes may have overlapping functions in vivo. That Sox 8 and Sox 10 are most highly expressed at $13.5 \mathrm{dpc}$ points towards roles for these genes in vivo in chondrocyte maturation, or in preparing chondrocytes for subsequent hypertrophy. Sox13 was upregulated from $11.5 \mathrm{dpc}$ to $12.5 \mathrm{dpc}$, to a level at which it was maintained until $13.5 \mathrm{dpc}$. The association of Sox13 with limb bud development has recently been demonstrated by immunohistochemistry [63].

Another large transcription factor family of which multiple members were found to exhibit dynamic patterns of differential expression was the forkhead box (Fox) gene family (Fig. 5J). Three Fox genes were very highly expressed. Notably, Foxc2 was significantly up-regulated, almost 3-fold between $11.5 \mathrm{dpc}$ and $12.5 \mathrm{dpc}$, and approximately 3.5 fold by $13.5 \mathrm{dpc}$. Furthermore, Foxo 1 and Foxp 1 were both strongly expressed, and differentially expressed during in vivo chondrogenesis, although the expression patterns of these transcription factors differed markedly. Whereas Foxo1 expression was found to increase in a linear fashion by almost 5 -fold between 11.5 
dpc and $13.5 \mathrm{dpc}$, Foxp1 expression peaked at $12.5 \mathrm{dpc}$, before dropping by greater than 3 -fold by $13.5 \mathrm{dpc}$. A further four Fox genes were moderately expressed. One of these genes, Foxa3, was dramatically up-regulated between $11.5 \mathrm{dpc}$ and $13.5 \mathrm{dpc}$, by over 20 -fold. Seven other Fox genes were weakly expressed and of these, only Foxd1 was differentially expressed, up-regulated more than 4 -fold from $11.5 \mathrm{dpc}$ to $13.5 \mathrm{dpc}$.

Only two Fox genes however, have been implicated in skeletogenesis to date. Foxa3 transcripts have been detected by in situ hybridization in the vertebrae and ribs of $14.5 \mathrm{dpc}$ mouse embryos [64], while expression of Foxc2 has been observed during axial and appendicular skeletogenesis in mouse. Interestingly, in the developing limb, it was found that Foxc2 transcripts localized to the periphery of the mesenchymal condensation at $12.5 \mathrm{dpc}$, and the perichondrium of the cartilage anlagen at 13.5 dpc [65]. The function of Foxa3 and Foxc2 during chondrogenesis remains unknown.

\section{Extracellular matrix molecules}

Chondrogenesis involves the secretion of a complex extracellular matrix rich in collagens and non-collagenous proteoglycans. Thus, it was expected that many genes encoding components of cartilage extracellular matrix would be dramatically up-regulated during in vivo chondrogenesis. The results which follow include the differential expression patterns observed for prominent noncollagenous extracellular matrix proteins as well as for the collagen gene family and the integrin family, which encode extracellular matrix receptors.

As predicted, many genes encoding cartilage extracellular matrix molecules were highly up-regulated (Fig. 5K). It was found that cartilage link protein (Hapln1, hyaluronan and proteoglycan link protein 1) was highly expressed, and by far the most highly up-regulated gene during in vivo chondrogenesis, its expression having increased approximately 200-fold between $11.5 \mathrm{dpc}$ and $13.5 \mathrm{dpc}$. Cartilage oligomeric matrix protein (Comp), aggrecan (Agc1), matrilin 1 (Matn1), and chondroitin sulphate proteoglycan 4 (Cspg4) were also highly expressed and very highly up-regulated between $11.5 \mathrm{dpc}$ and $13.5 \mathrm{dpc}$. Matrilin 3 (Matn3) and matrilin 2 (Matn2) were also very highly up-regulated, although they were expressed only moderately. The most highly expressed of these genes were Cspg4 and Matn4, although Matn4 was not found to be differentially expressed. Fibronectin 1 (Fn1) was not differentially expressed, and its expression was moderate. Versican (Vcan) expression was down-regulated by over 10-fold from $11.5 \mathrm{dpc}$ to $13.5 \mathrm{dpc}$ while Tenascin C $(\operatorname{TnC})$ expression was moderate but was up-regulated by almost 8 -fold. As with other components of the cartilage ECM, many collagen genes and integrins were differentially expressed during in vivo chondrogenesis (see Additional file 4).

\section{Ontology approaches identify a large cohort of novel genes expressed during chondrogenesis for further investigation}

The importance of this study is realised by the utility of the microarray data as an invaluable resource for investigating the roles of novel genes during in vivo chondrogenesis. In order to identify such genes, ontological approaches were undertaken to classify differentially expressed genes according to biological process and thus identify those for which an association with ontologies relating to cartilage and skeletal development has yet to be made. Accordingly, the 931 genes for which a differential expression of greater than three and a average $\log _{2}$ intensity of greater than or equal to six was observed between $11.5 \mathrm{dpc}-13.5 \mathrm{dpc}$ (see Additional file 2) were interrogated by GOstat software using the MGI GO gene association database http://gostat.wehi.edu.au/ in order to identify highly represented gene ontologies. As predicted, ontologies relating to cartilage and skeletal development were observed. Among the down-regulated genes, 9 were classified under 'skeletal development' (GO:0001501). Among the up-regulated genes, 30 were classified under 'skeletal development' (GO:0001501), 20 under 'ossification' (GO:0001503), 15 under 'cartilage development' (GO:0051216), 5 under 'chondrocyte differentiation' (GO:0002062), and 4 under 'cartilage condensation' (GO:0001502). Of these genes, 44 appeared under multiple classifications. Therefore, a total of 39 genes were classified by GOstat analysis as having previously been implicated in cartilage or skeletal development, leaving 892 novel genes for which an ontological association with chondrogenesis has yet to made. Thus, this study has served to identify a large cohort of novel genes whose expression or function during in vivo chondrogenesis is uncharacterized and potentially represents important developmental regulators. This dataset is therefore an important reference for future gene discovery and stands as an invaluable resource for ongoing research into skeletal development and disease.

Our studies are the first comprehensive attempt to identify genes which regulate the initiation of chondrogenesis in vivo. We have described the differential expression patterns observed for major gene families encoding adhesion molecules, transcription factors, and signalling molecules known to be important in many developmental processes, and have implicated members of these developmental gene families in chondrogenesis for the first time. In addition, we have identified many new candidate genes that may be involved in the initiation of chondrogenesis, on the basis of their differential expression patterns observed here, in combination with their known associa- 
tion with specific biological processes or known molecular function.

\section{Conclusion}

By conducting whole genome microarray analyses of RNA derived specifically from tissues representative of key stages of in vivo limb bud chondrogenesis, we have generated and thoroughly validated expression profiles which for the first time define the suite of genes expressed by chondrogenic tissues in the formation of cartilage from pre-condensed mesenchyme during embryogenesis. In doing so, we have defined the expression profiles of known chondrogenically and developmentally important gene families expressed by chondrogenic tissues during cartilage formation, and have identified 931 genes significantly differentially expressed during this process, consisting of large gene cohorts particular to each stage of cartilage development - pre-condensed mesenchyme, mesenchymal condensations, and cartilage anlagen. It is anticipated that these data will be important in further unravelling the fundamental control networks which drive cartilage development, in investigating the molecular pathology of inherited skeletal diseases, and in exploring which properties of pre-skeletal limb bud mesenchymal cells predispose them to efficient chondrogenic differentiation, the understanding of which promises to aid research into therapeutic cartilage repair. Thus, the data-set generated in this study stands as an important development for skeletal biology research.

\section{Methods \\ Microdissection of chondrogenic condensations and preparation of RNA}

We have previously reported global differential expression profiles corresponding to zones of the growth plate generated by microarray analysis of RNA derived from tissue microdissected from long bones of Swiss white mice [66]. So that these datasets could be compared with those of the present study, Swiss white mice were used here also. Accordingly, pregnant female Swiss white mice were sacrificed in accordance with Institutional Animal Ethics guidelines and embryos were harvested at $11.5 \mathrm{dpc}, 12.5$ $\mathrm{dpc}$ and $13.5 \mathrm{dpc}$ and transferred to PBS at $4{ }^{\circ} \mathrm{C}$. The hind limb buds were promptly dissected and embedded in Tissue-Tek OCT (Sakura Fine Technical), snap-frozen in isopentane and stored at $-80^{\circ} \mathrm{C} .6 \mu \mathrm{m}$ sections of limb tissue corresponding to the regions of tibial and fibular development were prepared using a cryostat (Leica CM1850), mounted on RNAse-free SuperFrost Plus slides (Biolab Scientific), fixed in $70 \%$ ethanol, washed in RNAse-free water, and dehydrated in $70 \%, 95 \%$, and $100 \%$ ethanol for thirty seconds each, and air-dried. Regions corresponding to the mesenchymal condensations of developing tibiae and fibulae were microdissected from slides immobilized on the stage of an inverted light microscope (Leica DM IL) using an ophthalmic scalpel (Feather) fixed to the scanning xy-object guide. Mesenchymal condensations and cartilage anlagen at $12.5 \mathrm{dpc}$ and $13.5 \mathrm{dpc}$ were readily visible in untreated (ie fixed and dehydrated, but not stained) sections by light microscopy, allowing precise microdissection of these tissues. In $12.5 \mathrm{dpc}$ hind limb sections, a prominent blood vessel was found to run between, and perpendicular to the developing tibia and fibula, thus appearing in the transverse plane as the tibia and fibula came into view (Fig. 6). The appearance of this blood vessel was used as a guide for locating the precondensed mesenchymal cells in $11.5 \mathrm{dpc}$ hind limb sections. 231 sections from a total of four $11.5 \mathrm{dpc}$ mouse hind limbs, three $12.5 \mathrm{dpc}$ mouse hind limbs, and four $13.5 \mathrm{dpc}$ mouse hind limbs were microdissected (Fig. 6). The tissue from each time point was pooled into RNasefree Eppendorf tubes and total RNA was extracted using the RNeasy Micro Kit (Qiagen). To assess RNA yield, purity, and integrity, total RNA samples were interrogated by capillary electrophoresis with a Bioanalyzer 2100 (Agilent Technologies), using a Series II RNA 6000 Pico Kit, according to the manufacturer's specifications (Agilent Technologies). All total RNA samples were confirmed to be of high quality, with a RIN of >7.7 (Agilent). Total RNA from tibial and fibular tissue microdissected from each time point was linearly amplified [67] in two rounds using the MessageAmp aRNA kit (Ambion) following the manufacturer's instructions. 100-150 ng of first-round amplified cRNA was used as template for each of the second round amplifications. Quality and yield was assessed by capillary electrophoresis. Amplified RNA samples $(1.25 \mu \mathrm{g})$ were fluorescently labelled with Cy3 or Cy5 fluorophores (Amersham) according to the manufacturer's instructions, analysed by $1.5 \%$ agarose gel electrophoresis, and visualized using a Typhoon fluorescence scanner (Amersham) (see Additional file 5). These data demonstrated that the majority of transcripts in each sample were approximately $150 \mathrm{nt}-400 \mathrm{nt}$ in length, and the lack of low molecular weight fluorescent signal confirmed that all unincorporated dyes were successfully removed during the purification procedure.

\section{Microarray hybridizations}

Interrogation of the $11.5 \mathrm{dpc}, 12.5 \mathrm{dpc}$, and $13.5 \mathrm{dpc}$ cRNA samples by microarray analysis involved a saturated hybridization strategy with dye swaps. Thus, cRNA samples from each time point were labelled with both $\mathrm{Cy} 3$ and Cy5 fluorophores, and six hybridizations were performed such that each time point was compared with each other time point using both dye combinations (to normalize against dye biases). $44 \mathrm{~K}$ whole mouse genome microarrays (G4122F, ID014868, Agilent) were hybridized according to the manufacturer's instructions. The arrays were then scanned at $10 \mu \mathrm{m}$ resolution on an Axon $4000 \mathrm{~B}$ scanner and the features acquired with the GenePix Pro 4.1 software (Axon Instruments). The raw data was then processed using a print-tip loess normalization [68] 

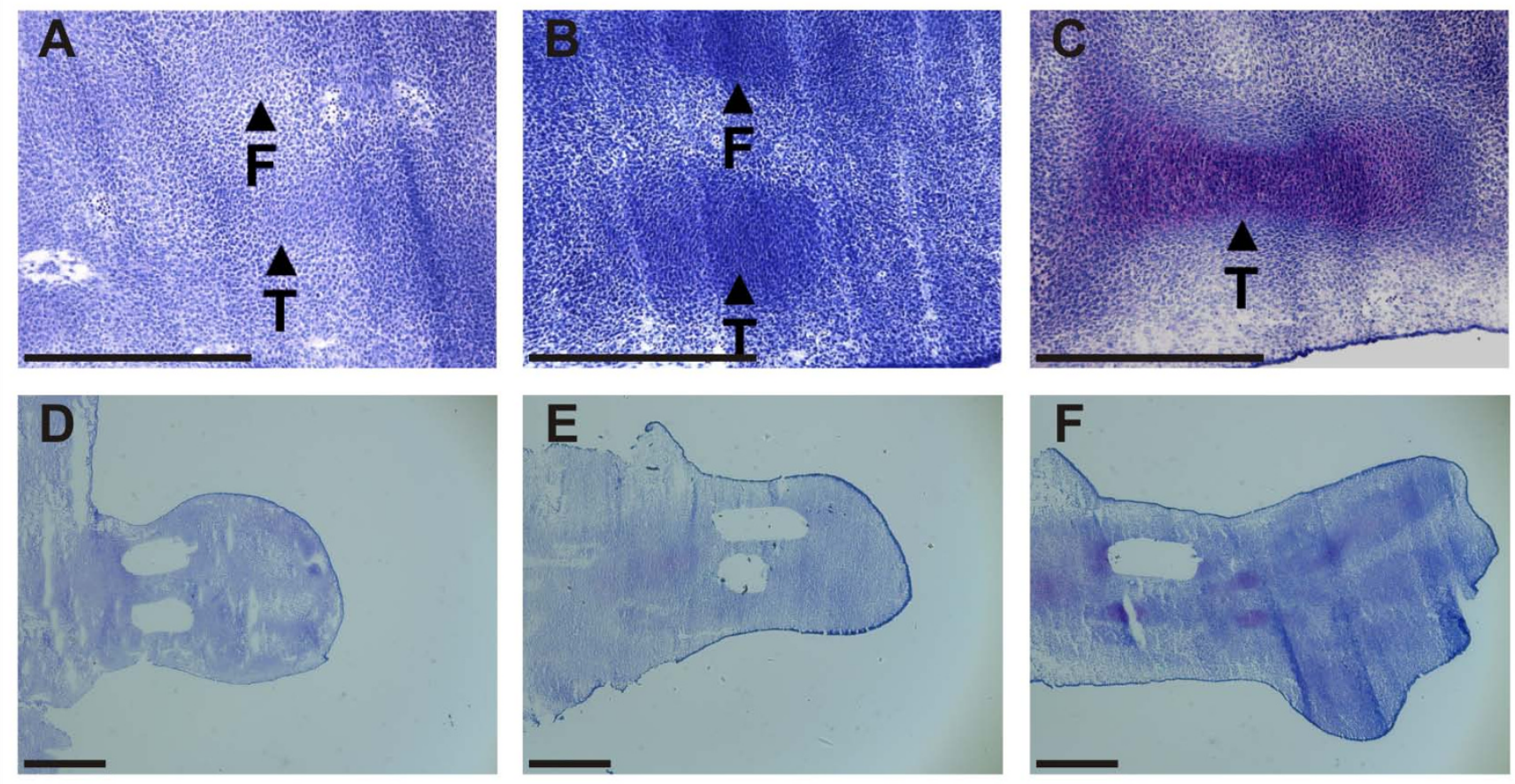

\section{Figure 6}

Mouse hindlimb microdissections. II.5 dpc, $12.5 \mathrm{dpc}$, and I $3.5 \mathrm{dpc}$ mouse hindlimb cryosections stained with Toluidine Blue. Upper panels (A-C) show intact tissue; lower panels (D-F) show cryosections following microdissection of tibial and fibular tissues. Staining of tissues shown in lower panels was performed following microdissection. $T=$ Tibia, F = Fibula. Scale bar $=500 \mu \mathrm{m}$.

using limmaGUI $[69,70]$ which is an implemented package of R used to fit linear models to microarray data http:/ /bioinf.wehi.edu.au/limma/. Genes were ranked according to their differential expression and gene lists were generated based on biological process and function (GOStat and OntoExpress).

\section{PCR analysis}

Semi-quantitative PCR was used for initial validation of the differential expression of specific genes during hind limb chondrogenesis. Reverse transcription reactions were performed using equal quantities of cRNA as template, to generate cDNA. Equal quantities of cDNA were used as template for PCR amplification of specific genes, using primers designed as close as possible to the end of the 3' untranslated region of the cDNA sequence. To ensure that the reactions were stopped during the linear phase of amplification, reactions were set up in triplicate and routinely removed from the thermocycler at 25 cycles, 30 cycles, and 35 cycles. Quantitative PCR (qPCR) was used for quantitative validation of the differential expression of specific genes during hind limb chondrogenesis. Primers for qPCR were designed using online software https:// www.roche-applied-science.com/sis/rtpcr/upl/adc.jsp. qPCR was performed using the FastStart TaqMan Probe Master real time PCR kit in $10 \mu \mathrm{l}$ reactions comprised of 5 $\mu \mathrm{l}$ Roche FastStart Probe Master (Rox), 50 ng cDNA, 240
nM additional ROX Reference Dye, 100 nM UPL Probe, and $200 \mathrm{nM}$ each primer. Thermal cycling was conducted on an Applied Biosystems 7700 Real-Time PCR System, as follows: initial denaturation at $95^{\circ} \mathrm{C}$ for 10 minutes, followed by 50 cycles of denaturation at $95^{\circ} \mathrm{C}$ for $30 \mathrm{sec}-$ onds, annealing and polymerization at $60^{\circ} \mathrm{C}$ for one minute. qPCR data were analyzed using Applied Biosystems SDS 2.2.2 software. All primer sequences are available on request.

\section{Histology}

Toluidine Blue staining with Fast Green counter-staining [71] was used to detect accumulation of proteoglycans in sagittal cryosections of embryonic mouse limb buds, as a histological assay for chondrogenesis.

\section{In situ hybridization}

Hindlimbs from E11.5, 12.5 and 13.5 embryos were fixed overnight in 4\% PFA then cyroprotected by immersion in $30 \%$ sucrose overnight. $12 \mu \mathrm{m}$ frozen sections were then subjected to in situ hybridization for each gene [72].

\section{Abbreviations}

aRNA: amplified RNA; cRNA: complementary RNA; dpc: days post coitum; GO: gene ontology; qPCR: quantitative PCR; RT-PCR: reverse transcription PCR. 


\section{Authors' contributions}

TLC carried out all tissue preparations including dissection and microdissection, RNA purification and amplification, semi-quantitative and quantitative PCR analyses, microarray hybridizations (in conjunction with DB), and histology. DB conducted the initial microarray data analysis. PGF designed and generated probes for, and carried out the in situ hybridizations. JFB co-ordinated the study. TLC and JFB drafted the manuscript. All authors contributed to the design of the study, and critically reviewed and approved the final manuscript.

\section{Additional material}

\section{Additional file 1}

Major categories of molecular function of genes differentially expressed during chondrogenesis. The data provided represent the 931 genes significantly (>3-fold) up-regulated (A) or down-regulated (B) during chondrogenesis (see Additional file 2 for gene list) after mining using OntoExpress gene ontology software and clustering according biological process.

Click here for file

[http://www.biomedcentral.com/content/supplementary/1471213X-9-20-S1.tiff]

\section{Additional file 2}

List of genes differentially up- or down-regulated ( $>3$-fold) during chondrogenesis. The data provided represent the cohort of genes whose $\log _{2}$ intensity (A) was above background level, and whose expression changed by greater than 3-fold during chondrogenesis in the mouse limb between $11.5 \mathrm{dpc}$ and $13.5 \mathrm{dpc}$.

Click here for file

[http://www.biomedcentral.com/content/supplementary/1471-

213X-9-20-S2.doc]

\section{Additional file 3}

Validation of microarray expression data by comparative literature analysis. The data provided represent the differential expression profiles for a list of 50 genes whose differential expression during chondrogenesis have been corroborated elsewhere in the scientific literature, and includes specific references to which the reader is directed for each gene.

Click here for file

[http://www.biomedcentral.com/content/supplementary/1471213X-9-20-S3.doc]

\section{Additional file 4}

Differential expression of collagens and integrins during chondrogenesis. The data provided represent the differential expression profiles of the (A) collagens, B) alpha-integrins (Itga), and C) beta-integrins (Itgb) during chondrogenesis in the mouse limb between $11.5 \mathrm{dpc}$ and $13.5 \mathrm{dpc}$. Yellow bars indicate relative expression at $11.5 \mathrm{dpc}$. Blue bars indicate relative expression at $12.5 \mathrm{dpc}$. Orange bars indicate relative expression at $13.5 \mathrm{dpc}$. For each gene, the time point at which the relative expression was lowest was defined as one, and this was used to calculate the relative expression at the remaining time points. Numbers above each gene denote average $\log _{2}$ intensity (A) for that gene.

Click here for file

[http://www.biomedcentral.com/content/supplementary/1471-

213X-9-20-S4.tiff]

\section{Additional file 5}

Agarose gel electrophoresis for cRNA samples from $11.5 \mathrm{dpc}, 12.5 \mathrm{dpc}$, or $13.5 \mathrm{dpc}$ following labelling with $\mathrm{C} y 3$ or $\mathrm{C} y 5$ fluorophores. This agarose gel indicates successful labelling of the cRNA samples from 11.5 $d p c-13.5$ dpc mouse limb chondrogenic tissues with Cy3 or Cy5 fluorophores, and verifies that unincorporated dyes were removed from the cRNA samples during purification.

Click here for file

[http://www.biomedcentral.com/content/supplementary/1471213X-9-20-S5.tiff]

\section{Acknowledgements}

This work was supported by grants from the National Health and Medical Research Council of Australia and the Murdoch Childrens Research Institute. The authors thank the Murdoch Childrens Research Institute Bioinformatics Unit, for assistance with gene ontology analysis.

\section{References}

I. DeLise AM, Fischer L, Tuan RS: Cellular interactions and signaling in cartilage development. Osteoarthritis Cartilage 2000, 8:309-34.

2. Hall BK, Miyake T: All for one and one for all: condensations and the initiation of skeletal development. Bioessays 2000, 22:138-47.

3. Shum L, Nuckolls G: The life cycle of chondrocytes in the developing skeleton. Arthritis Res 2002, 4:94-106.

4. Goldring MB, Tsuchimochi K, ljiri K: The control of chondrogenesis. J Cell Biochem 2006, 97:33-44.

5. Karsenty G, Wagner EF: Reaching a genetic and molecular understanding of skeletal development. Dev Cell 2002, 2:389-406.

6. Cancedda R, Descalzi-Cancedda F, Castagnola P: Chondrocyte differentiation. International Review of Cytology 1994, 159:265-358.

7. Zelzer $E$, Olsen BR: The genetic basis for skeletal diseases. Nature 2003, 423:343-8.

8. Geetha-Loganathan P, Nimmagadda S, Huang R, Scaal M, Christ B: Expression pattern of BMPs during chick limb development. Anat Embryol (Berl) 2006, 21 I (Suppl I):87-93.

9. Francis PH, Richardson MK, Brickell PM, Tickle C: Bone morphogenetic proteins and a signalling pathway that controls patterning in the developing chick limb. Development 1994, 1 20:209-18.

10. Pizette $S$, Niswander L: BMPs are required at two steps of limb chondrogenesis: formation of prechondrogenic condensations and their differentiation into chondrocytes. Developmental Biology 2000, 21 9:237-49.

II. Tsumaki N, Nakase T, Miyaji T, Kakiuchi M, Kimura T, Ochi T, Yoshikawa $\mathrm{H}$ : Bone morphogenetic protein signals are required for cartilage formation and differently regulate joint development during skeletogenesis. Journal of Bone \& Mineral Research 2002, 17:898-906.

12. Lefebvre V, Huang W, Harley VR, Goodfellow PN, de Crombrugghe B: SOX9 is a potent activator of the chondrocyte-specific enhancer of the pro alphal(II) collagen gene. Mol Cell Biol 1997, 17:2336-46.

13. Lefebvre V, Li P, de Crombrugghe B: A new long form of Sox5 (LSox 5$)$, Sox 6 and Sox 9 are coexpressed in chondrogenesis and cooperatively activate the type II collagen gene. EMBO Journal 1998, 17:5718-33.

14. Dessau W, Mark H von der, Mark K von der, Fischer S: Changes in the patterns of collagens and fibronectin during limb-bud chondrogenesis. J Embryol Exp Morphol 1980, 57:5I-60.

15. Mackie EJ, Thesleff I, Chiquet-Ehrismann R: Tenascin is associated with chondrogenic and osteogenic differentiation in vivo and promotes chondrogenesis in vitro. J Cell Biol 1987, 105:2569-79.

16. Nishiyama A, Dahlin KJ, Stallcup WB: The expression of NG2 proteoglycan in the developing rat limb. Development 1991, I I I:933-44. 
17. Gould SE, Upholt WB, Kosher RA: Syndecan 3: a member of the syndecan family of membrane-intercalated proteoglycans that is expressed in high amounts at the onset of chicken limb cartilage differentiation. Proc Natl Acad Sci USA 1992, 89:327I-5.

18. Fernandez-Teran M, Bayliss M, Archer CW: Molecular heterogeneity of chondroitin sulphate in the early developing chick wing bud. Anat Embryol (Berl) 1993, 188:189-99.

19. Poole AR, Kojima T, Yasuda T, Mwale F, Kobayashi M, Laverty S Composition and structure of articular cartilage: a template for tissue repair. Clin Orthop 200I:S26-33.

20. Ratcliffe A, Mow VC: Articular Cartilage. In Extracellular Matrix Volume I. Edited by: Comper WD. Amsterdam: Harwood Academic Publishers; 1996:234-302.

21. Eyre D: Collagen of articular cartilage. Arthritis Res 2002, 4:30-5.

22. Li Y, Olsen BR: Murine models of human genetic skeletal disorders. Matrix Biol 1997, 16:49-52.

23. Aszodi A, Bateman JF, Gustafsson E, Boot-Handford R, Fassler R: Mammalian skeletogenesis and extracellular matrix: what can we learn from knockout mice? Cell Struct Funct 2000 25:73-84.

24. Roughley PJ: Articular cartilage and changes in arthritis: noncollagenous proteins and proteoglycans in the extracellular matrix of cartilage. Arthritis Res 200I, 3:342-7.

25. Hocking AM, Shinomura T, McQuillan DJ: Leucine-rich repeat glycoproteins of the extracellular matrix. Matrix Biol 1998 17:1-19.

26. Heinegard D, Oldberg A: Structure and biology of cartilage and bone matrix noncollagenous macromolecules. FASEB J 1989 3:2042-205।

27. Svensson L, Oldberg A, Heinegard D: Collagen binding proteins. Osteoarthritis Cartilage 200I, 9(Suppl A):S23-8.

28. Hecht J, Seitz V, Urban M, Wagner F, Robinson PN, Stiege A, Dieterich C, Kornak U, Wilkening U, Brieske N, et al: Detection of novel skeletogenesis target genes by comprehensive analysis of a Runx2(-/-) mouse model. Gene Expr Patterns 2007, 7:102-12.

29. Sugars RV, Karner E, Petersson U, Ganss B, Wendel M: Transcriptome analysis of fetal metatarsal long bones by microarray, as a model for endochondral bone formation. Biochim Biophys Acta 2006, 1763:1031-9.

30. James CG, Appleton CT, Ulici V, Underhill TM, Beier F: Microarray analyses of gene expression during chondrocyte differentiation identifies novel regulators of hypertrophy. Mol Biol Cell 2005, 16:5316-33

31. Sekiya I, Vuoristo JT, Larson BL, Prockop DJ: In vitro cartilage formation by human adult stem cells from bone marrow stroma defines the sequence of cellular and molecular events during chondrogenesis. Proc Natl Acad Sci USA 2002, 99:4397-402.

32. Tallheden T, Karlsson C, Brunner A, Lee J Van Der, Hagg R, Tommasini $R$, Lindahl $A$ : Gene expression during redifferentiation of human articular chondrocytes. Osteoarthritis \& Cartilage 2004, I 2:525-35

33. Oberlender SA, Tuan RS: Expression and functional involvement of $\mathbf{N}$-cadherin in embryonic limb chondrogenesis. Development 1994, 1 20: 177-87.

34. Zaucke F, Dinser R, Maurer P, Paulsson M: Cartilage oligomeric matrix protein (COMP) and collagen $I X$ are sensitive markers for the differentiation state of articular primary chondrocytes. Biochem J 200I, 358: 17-24.

35. Suzuki ST: Recent progress in protocadherin research. Exp Cell Res 2000, 261:13-8.

36. Makarenkova $\mathrm{H}$, Sugiura $\mathrm{H}$, Yamagata $\mathrm{K}$, Owens G: Alternatively spliced variants of protocadherin 8 exhibit distinct patterns of expression during mouse development. Biochim Biophys Acta 2005, I 68I:150-6.

37. Halbleib JM, Nelson W]: Cadherins in development: cell adhesion, sorting, and tissue morphogenesis. Genes \& Development 2006, 20:3199-214.

38. Matsusaki T, Aoyama T, Nishijo K, Okamoto T, Nakayama T, Nakamura T, Toguchida J: Expression of the cadherin-II gene is a discriminative factor between articular and growth plate chondrocytes. Osteoarthritis Cartilage 2006, 14:353-66.

39. Luo Y, Kostetskii I, Radice GL: N-cadherin is not essential for limb mesenchymal chondrogenesis. Developmental Dynamics 2005, 232:336-44.
40. Denker AE, Haas AR, Nicoll SB, Tuan RS: Chondrogenic differentiation of murine $\mathrm{C} 3 \mathrm{HIOTI} / 2$ multipotential mesenchymal cells: I. Stimulation by bone morphogenetic protein-2 in high-density micromass cultures. Differentiation 1999, 64:67-76.

4I. Buckland RA, Collinson JM, Graham E, Davidson DR, Hill RE: Antagonistic effects of FGF4 on BMP induction of apoptosis and chondrogenesis in the chick limb bud. Mech Dev 1998, 71:143-50.

42. King M, Arnold JS, Shanske A, Morrow BE: T-genes and limb bud development. American Journal of Medical Genetics. Part A 2006, 140:1407-13

43. Solloway MJ, Dudley AT, Bikoff EK, Lyons KM, Hogan BL, Robertson EJ: Mice lacking Bmp6 function. Developmental Genetics 1998, 22:32I-39.

44. Yi SE, Daluiski A, Pederson R, Rosen V, Lyons KM: The type I BMP receptor BMPRIB is required for chondrogenesis in the mouse limb. Development 2000, 127:62I-30.

45. DiLeone RJ, King JA, Storm EE, Copeland NG, Jenkins NA, Kingsley DM: The Bmp8 gene is expressed in developing skeletal tissue and maps near the Achondroplasia locus on mouse chromosome 4. Genomics 1997, 40:196-8.

46. Coleman CM, Loredo GA, Lo CW, Tuan RS: Correlation of GDF5 and connexin 43 mRNA expression during embryonic development. Anatomical Record. Part A, Discoveries in Molecular, Cellular, \& Evolutionary Biology 2003, 275: I I 17-2I.

47. Meech R, Edelman DB, Jones FS, Makarenkova HP: The homeobox transcription factor $B$ arx 2 regulates chondrogenesis during limb development. Development 2005, 132:2135-46.

48. SH Settle Jr, Rountree RB, Sinha A, Thacker A, Higgins K, Kingsley DM: Multiple joint and skeletal patterning defects caused by single and double mutations in the mouse Gdf6 and Gdf5 genes. Developmental Biology 2003, 254: I I6-30.

49. Cho TJ, Gerstenfeld LC, Einhorn TA: Differential temporal expression of members of the transforming growth factor beta superfamily during murine fracture healing. Journal of Bone \& Mineral Research 2002, 17:513-20.

50. Church V, Nohno T, Linker C, Marcelle C. Francis-West P: Wnt regulation of chondrocyte differentiation. J Cell Sci 2002, I I 5:4809-18.

51. Hartmann C, Tabin C): Dual roles of Wnt signaling during chondrogenesis in the chicken limb. Development 2000, I27:3|4|-59.

52. Ornitz DM, Marie PJ: FGF signaling pathways in endochondral and intramembranous bone development and human genetic disease. Genes Dev 2002, 16: 1446-65

53. Liu Z, Lavine $\mathrm{KJ}$, Hung IH, Ornitz DM: FGFI 8 is required for early chondrocyte proliferation, hypertrophy and vascular invasion of the growth plate. Developmental Biology 2007, 302:80-9I.

54. Marics I, Padilla F, Guillemot JF, Scaal M, Marcelle C: FGFR4 signaling is a necessary step in limb muscle differentiation. Development 2002, I 29:4559-69.

55. Massip L, Ectors F, Deprez P, Maleki M, Behets C, Lengele B, Delahaut $P$, Picard J, Rezsohazy R: Expression of Hoxa2 in cells entering chondrogenesis impairs overall cartilage development. Differentiation 2007, 75:256-67.

56. Akiyama H, Stadler HS, Martin JF, Ishii TM, Beachy PA, Nakamura T, de Crombrugghe B: Misexpression of Sox9 in mouse limb bud mesenchyme induces polydactyly and rescues hypodactyly mice. Matrix Biol 2007, 26:224-33.

57. Akiyama H, Chaboissier MC, Martin JF, Schedl A, de Crombrugghe B: The transcription factor Sox 9 has essential roles in successive steps of the chondrocyte differentiation pathway and is required for expression of Sox5 and Sox6. Genes Dev 2002, 16:2813-28

58. Foster JW, Dominguez-Steglich MA, Guioli S, Kowk G, Weller PA Stevanovic M, Weissenbach J, Mansour S, Young ID, Goodfellow PN, et al.: Campomelic dysplasia and autosomal sex reversal caused by mutations in an SRY-related gene. Nature 1994, 372:525-30

59. Lefebvre V, de Crombrugghe B: A new long form of Sox5 (LSox5), Sox6 and Sox 9 are co-expressed in chondrogenesis and cooperatively activate the type II collagen gene. EMBO J 1998, 17:5718-5733.

60. Reppe S, Rian E, Jemtland R, Olstad OK, Gautvik VT, Gautvik KM Sox-4 messenger RNA is expressed in the embryonic growth plate and regulated via the parathyroid hormone/parathy- 
roid hormone-related protein receptor in osteoblast-like cells. J Bone Miner Res 2000, 15:2402-12.

61. Maschhoff KL, Anziano PQ, Ward P, Baldwin HS: Conservation of Sox4 gene structure and expression during chicken embryogenesis. Gene 2003, 320:23-30.

62. Chimal-Monroy J, Rodriguez-Leon J, Montero JA, Ganan Y, Macias D, Merino R, Hurle JM: Analysis of the molecular cascade responsible for mesodermal limb chondrogenesis: Sox genes and BMP signaling. Dev Biol 2003, 257:292-30I.

63. Wang Y, Ristevski S, Harley VR: SOX 13 exhibits a distinct spatial and temporal expression pattern during chondrogenesis, neurogenesis, and limb development. I Histochem Cytochem 2006, 54:1327-33

64. Monaghan AP, Kaestner KH, Grau E, Schutz G: Postimplantation expression patterns indicate a role for the mouse forkhead/ HNF-3 alpha, beta and gamma genes in determination of the definitive endoderm, chordamesoderm and neuroectoderm. Development 1993, I1 9:567-78.

65. Nifuji A, Miura N, Kato N, Kellermann O, Noda M: Bone morphogenetic protein regulation of forkhead/winged helix transcription factor Foxc2 (MfhI) in a murine mesodermal cell line $\mathrm{CI}$ and in skeletal precursor cells. Journal of Bone \& Mineral Research 2001, 16: 1765-71.

66. Belluoccio D, Bernardo BC, Rowley L, Bateman JF: A microarray approach for comparative expression profiling of the discrete maturation zones of mouse growth plate cartilage. Biochim Biophys Acta 2008, 1779:330-40.

67. Van Gelder RN, von Zastrow ME, Yool A, Dement WC, Barchas JD, Eberwine $\mathrm{JH}$ : Amplified RNA synthesized from limited quantities of heterogeneous cDNA. Proc Natl Acad Sci USA 1990, 87:1663-7.

68. Smyth GK, Speed T: Normalization of cDNA microarray data. Methods 2003, $31: 265-73$.

69. Smyth GK: Limma: linear models for microarray data. In Bioinformatics and Computational Biology Solutions using $R$ and Bioconductor Springer; 2005:397-420.

70. Wettenhall JM, Smyth GK: limmaGUI: a graphical user interface for linear modeling of microarray data. Bioinformatics 2004, 20:3705-6.

7I. Naumann A, Dennis JE, Awadallah A, Carrino DA, Mansour JM, Kastenbauer E, Caplan Al: Immunochemical and mechanical characterization of cartilage subtypes in rabbit. I Histochem Cytochem 2002, 50:1049-58.

72. Dunwoodie SL, Henrique D, Harrison SM, Beddington RS: Mouse DII3: a novel divergent Delta gene which may complement the function of other Delta homologues during early pattern formation in the mouse embryo. Development 1997, I 24:3065-76.
Publish with Bio Med Central and every scientist can read your work free of charge

"BioMed Central will be the most significant development for disseminating the results of biomedical research in our lifetime. "

Sir Paul Nurse, Cancer Research UK

Your research papers will be:

- available free of charge to the entire biomedical community

- peer reviewed and published immediately upon acceptance

- cited in PubMed and archived on PubMed Central

- yours - you keep the copyright
BioMedcentral 